\title{
PROTECTING THE SHORELINE OF THE SAN FRANCISCO INTERNATIONAL AIRPORT FROM SEA LEVEL RISE
}

\author{
Anna Johnson, Moffatt \& Nichol, ajohnson@moffattnichol.com \\ Dilip Trivedi, Moffatt \& Nichol, dtrivedi@moffattnichol.com \\ Kevin Hanegan, Moffatt \& Nichol, khanegan@moffattnichol.com \\ Rosalyn Yu, San Francisco International Airport, rosalyn.yu@flysfo.com
}

\section{INTRODUCTION}

The San Francisco International Airport (SFIA) has approximately eight miles of shoreline along San Francisco Bay. It was built on a series of land reclamations constructed between 1927 and 1972 . Primary consolidation and secondary settlement are still ongoing and expected to continue for 10 to 30 more years (M\&N 2015).

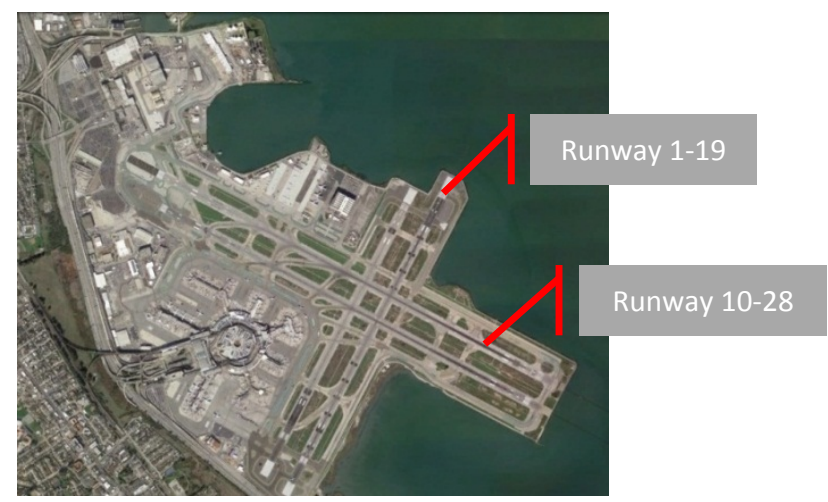

Figure 1 - SFIA Shoreline and Runways

The length of shoreline makes SFIA susceptible to flooding. The flood risk is expected to increase with ongoing settlement and future sea level rise (SLR). A system of seawalls has been constructed along the perimeter to protect the airport from flooding.

The shoreline along SFIA includes the end of Runway 119 and Runway 10-28, shown in Figure 1. Because the Federal Aviation Administration (FAA) requires that the end of runways be object-free areas (OFA), which prohibit seawalls from encroaching into the airspace and limits the allowable elevation, protection against future sea level rise (SLR) must be achieved without raising the seawalls. With SLR projections in San Francisco Bay of 1 foot by 2050 and 3 feet by 2100 (NRC 2012), SFIA decided to investigate alternative forms of flood protection at the end of the runways. Presented here is a feasibility study of alternative solutions.

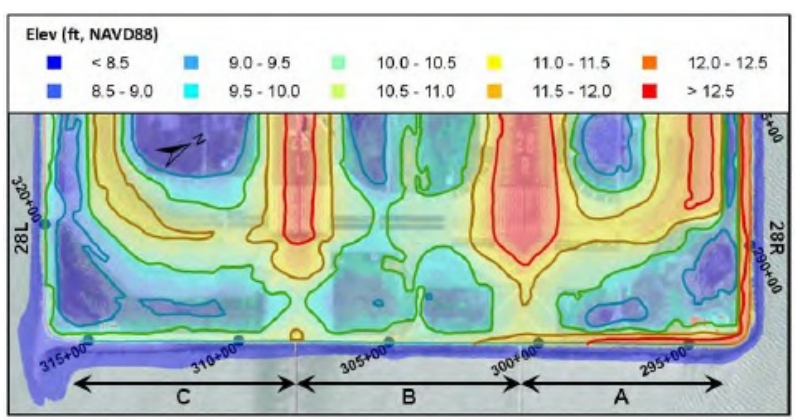

Figure 2 - Elevations along the end of Runway 10-28

\section{FLOODING POTENTIAL ASSESSMENT}

A coastal engineering assessment was conducted to determine the flooding potential along the SFIA shoreline. As there is no long term record of water levels in the vicinity of SFIA, a 34-year forecast of hourly water levels was generated from the NOAA-established tidal constituents and tidal residuals from a neighboring longterm tide station. This 'synthetic' time-series was verified against two short term tide stations in close proximity to the airport.

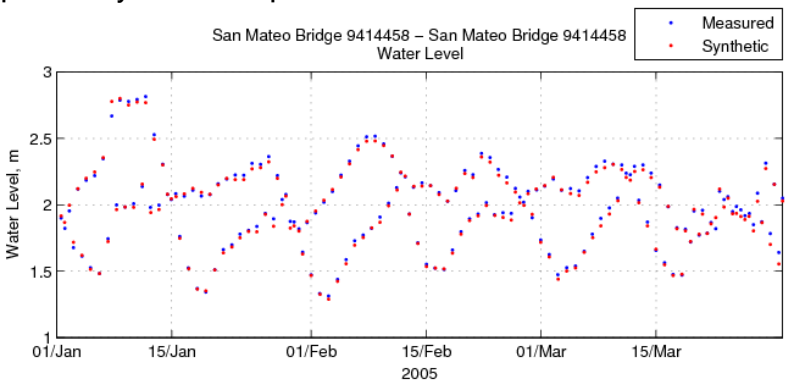

Figure 3 - Comparison between Measured and Synthetic High Tides at San Mateo Bridge (NOAA Station 9414588)

A time series of waves for the same duration was developed by simulating multiple combinations of water levels, wind speeds and wind directions from the airportoperated meteorological station, KSFO, using the MIKE21 Spectral Wave model.

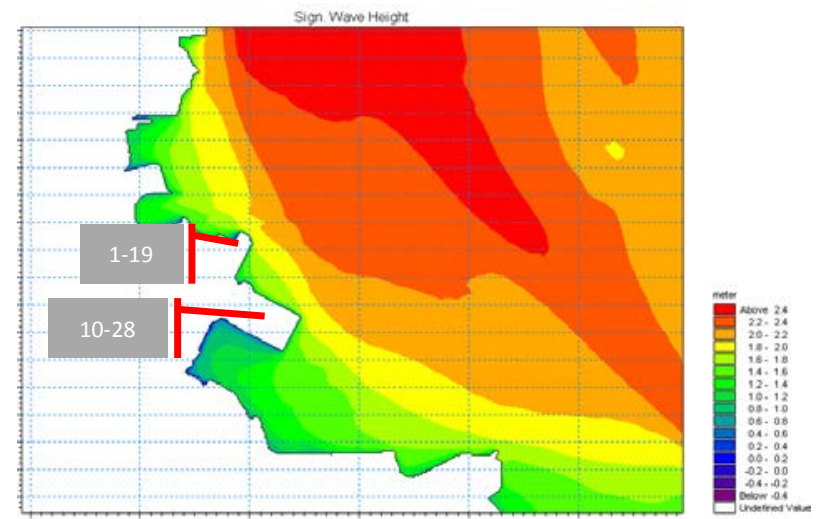

Figure 4 - Example Wave Model Result - Significant Wave Height for $30 \mathrm{~m} / \mathrm{s}$ wind speed at $90^{\circ}$ and $3 \mathrm{~m}$ NAVD88 Water Level

The hourly wave heights associated with the 34-year wind and water level data was established by linearly interpolating between the simulated combinations. This analysis resulted in a 34-year time series of water levels and wave data.

The $2 \%$ wave runup on the rock revetment along the runway ends was estimated using the Van der Meer equations described in the EurOtop Manual (Pullen, et al. 2007). These wave runup values were then added to 
the water levels to determine the total water level (TWL), or maximum water level accounting for both tide and wave effects, for each hour of the 34-year time series. An extreme value analysis was performed on the annual maximums of the TWL time series to determine the return-period TWL along the runway ends.

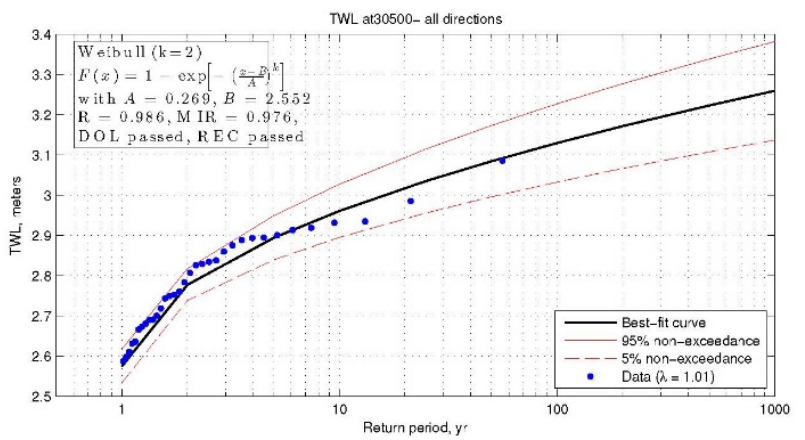

Figure 5 - Return period Total Water Level at the end of Runway $10-28$

Short and long term SLR values were added to the TWL to determine the future flooding potential.

\section{FLOOD PROTECTION ALTERNATIVES}

For short term SLR, the dominant flood source at the runway ends is overtopping waves. The flood risk could be mitigated by the installation of a breakwater (sheetpile or floating) to attenuate the waves. However, environmental permitting agencies regulating work in San Francisco Bay discourage construction in Bay waters. Therefore, the proposed alternative is to create a coastal embankment by removing the seawall and grading the area from the runway ends down to the water's edge. This would allow for waves to runup the bank and safely drain back to the Bay.

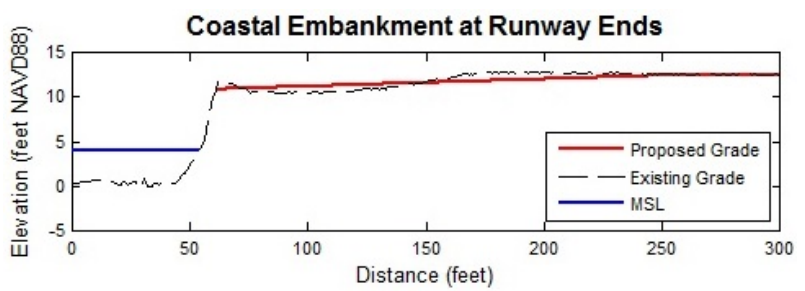

Figure 6 - Coastal Embankment at Runway Ends

The wave runup component of the TWL was recalculated for a combined slope (riprap slope and graded area). The results show that this alternative would protect the taxiways from approximately 1.5 feet of SLR and the runways from 2 feet of SLR.

For long term SLR (greater than 2 foot), flood events could result in water flowing over portions of the runways. In-water construction is likely unavoidable for this condition. The proposed alternative entails an offshore sheetpile breakwater that encloses the runway ends (Figure 7), creating a lagoon with controlled water levels. The breakwater would be positioned at a sufficient distance from the runway end to prevent it from encroaching into the OFA. This alternative could be adapted for higher SLR by raising the elevation of the sheetpile wall, provided that the acceptable OFA is maintained.
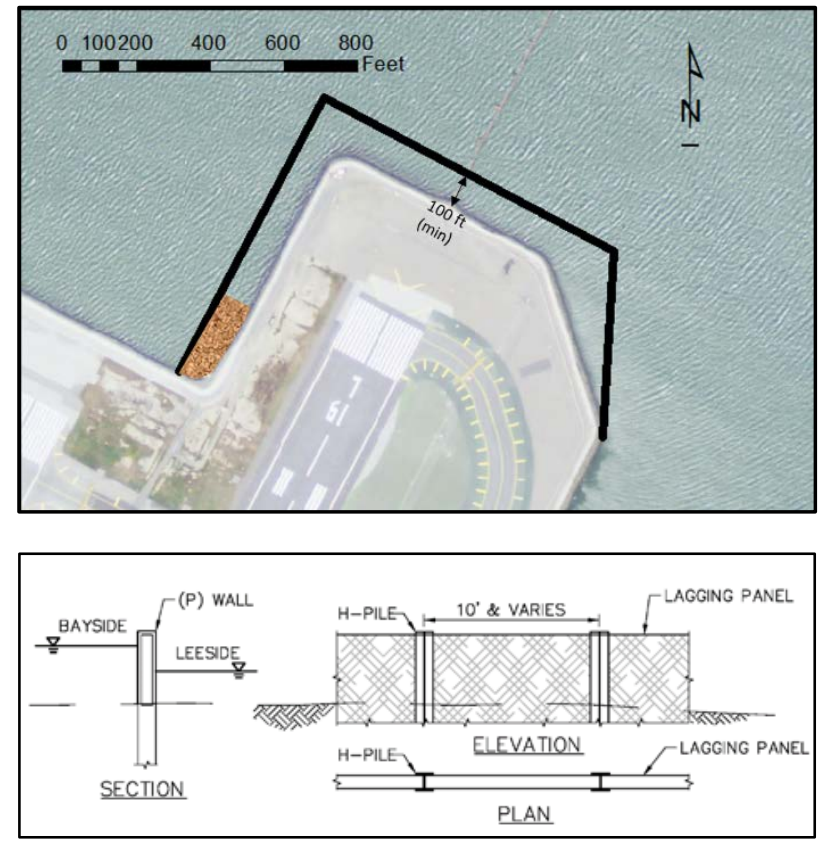

Figure 7 - Long Term SLR Offshore Breakwater

\section{REFERENCES}

Moffatt \& Nichol (2015): San Francisco International Airport Shoreline Protection Feasibility Study- Evaluation and Recommendations Report.

National Research Council Committee on Sea Level Rise in California, Oregon, and Washington (2012): Sea-Level Rise for the Coasts of California, Oregon, and Washington: Past, Present, and Future.

Pullen, T., Allsop, N.W.H., Bruce, T., Kortenhaus, A., Schuttrumpf, H., \& van der Meer, J.W. (2007). EurOtop Wave Overtopping of Sea Defences and Related Structures: Assessment Manual. Die Kuste, 73, 193. 